ever, when the solid is heated, sufficient energy is provided for the defect structure to decompose to chloride on heating. At $50^{\circ} \mathrm{C}$. the later decrease in chloride is presumably due to recombination of chloride with the oxygen atoms to reform chlorate. At higher temperatures, this recombination is less complete, probably because of competing reactions such as diffusion of oxygen atoms away from the damage site or by combination of oxygen atoms to form oxygen molecules.

P. F. Patrick

Department of Chemistry,

K. J. McCaxuUM

University of Saskatchewan, Saskatoon, Canada.

' Heal, H. G., Canad. J. Chem., 37, 979 (1959).

${ }^{2}$ Baberkin, T. P. V., Soveschaniya po Radiatsion Khem. Akad. Nauk, S.S.R., 167 (Otdel, Khim. Nauk, Moscow, 1957)

${ }^{3}$ Burchill, C. E., M.A. thesis, Univ. of Saskatchewan (1960).

\section{Electron Spin Resonance in $\gamma$-Irradiated Deoxyribonucleic Acid}

During the past five years radiation-induced free radicals in deoxyribonucleic acid (DNA) have been the object of studies using electron spin resonance ${ }^{1-5}$. In particular, some work in this field was undertaken in our laboratory ${ }^{6}$ with the main result that the yield of free radicals from $\gamma$-rays depends on the dose-rate.

The present communication summarizes some new results obtained using DNA from trout sperm which, irradiated in air at a temperature of $30^{\circ} \mathrm{C}$. with $\gamma$-rays of cobalt-60, gave rise to a remarkable structure of the resonance line. The sample contained $0 \cdot 1$ per cent by weight of protein, approximately 20 per cent of water and a trace of sodium acetate. A conventional X-band electron spin resonance spectrometer with reflexion cavity was used. The external mag. netic field was modulated at $416 \mathrm{c} . / \mathrm{s}$. and the first derivatives of the absorption curves were recorded after selective amplification and phase sensitive detection.

Fig. 1 shows a typical spectrum recorded $2 \mathrm{hr}$. after irradiation at a rate of $5 \times 10^{5} \mathrm{r}$. $/ \mathrm{hr}$. to a dose of $3 \times 10^{7} \mathrm{r}$. It consists of a central peak and two less-intense non-symmetrical side peaks. The central peak has a width at maximum slope of 10 œrsteds and its $G$ value is $2 \cdot 003 \pm 0.003$. The number of free radicals per gram measured from the total area under the curve is $3.6 \times 10^{15}$. The radiation yield $G$ is $2 \times 10^{-4}$ as compared with $9 \times 10^{-4}$ obtained previously by $\mathbf{u s}^{6}$ with commercial samples of DNA from herring sperm irradiated in air at the same rate. It should be mentioned that yields of $9 \times 10^{-4}$ and $2 \times 10^{-1}$ have been obtained with $\gamma$-rays by Blumenfeld $^{3}$ and Alexander ${ }^{5}$ respectively on DNA's of different origins. However in these cases, the irradiations were performed in vacuo so that only doubtful comparisons may be drawn. We have indeed shown

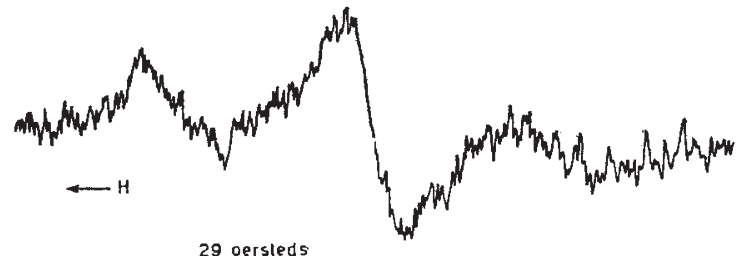

Fig. 1. First differential of electron spin resonance signals of $\gamma$-irradiated DNA (trout sperm) 2 hr. after irradiation that the $G$ values obtained even with identical samples of DNA from herring sperm irradiated by example at a rate of $2.7 \times 10^{4} \mathrm{r}$. $/ \mathrm{hr}$. to a dosage of $34 \times 10^{6} \mathrm{r}$. are greatly affected by the external conditions ${ }^{7}$ and are in fact much greater in vacuo $\left(24 \times 10^{-4}\right)$ than in air $\left(1.9 \times 10^{-4}\right)$

In the present experiments, both the shape and the intensity of the resonance line was found to vary with time. Four hours after the end of irradiation the central line was practically unchanged, though the heights of the derivatives of the side lines had decreased significantly. But, after $24 \mathrm{hr}$., the central line width had become 14 cersteds whereas the side lines were so smeared out and the signal-to-noise was so bad that they could not be measured with any accuracy. In these conditions, the total number of unpaired spins may only be tentatively estimated as being 45 per cent less than in the initial state.

We thank Prof. J. Duchesne for helpful discussions, Prof. J. A. V. Butler and Dr. P. Alexander for samples of DNA, and the Centre d'Etude de l'Energie Nucléaire, Mol, for providing irradiation facilities.

\section{DORLET \\ A. VAN DE VORST \\ A. J. Bertinchamps *}

Institut d'Astrophysique,

University of Liège.

* Present address: Euratom, rue Belliard, Brussels, Belgium.

Shields, H., and Gordy, W., Bull. Amer. Phys. Soc., Ser. 2, 1, 267 (1956).

${ }^{2}$ Gordy, W., Rad. Res., Supp. 1, 491 (1959)

shen-Pei-Guen, Blumenfeld, L. A., Kalmanson, A. E., and Pasynski, A. G., Biophysica, U.S.S.R., 4, 263 (1959)

- Boag, J. W., and Müller, A., Nature, 183, 831 (1959).

${ }^{5}$ Alexander, P., Lett, J. J., and Ormerod, M. G., Biochim. Biophys. Acta, 51, 207 (1961)

6 Van de Vorst, A., Van der Kaa, J. M., Duchesne, J., Depireux, J., and Bertinchamps, A., Bull. Ampère, geme année, Spec. Fasc. 1960)

${ }^{7}$ Van de Vorst, A., and Dorlet, C. (unpublished results).

\section{CHEMISTRY}

\section{Catastrophic Failure of Stressed Polyethylene Terephthalate}

In has recently been reported ${ }^{1}$ that nylon and 'Plexiglas' plates, if subjected to a bending stress in a vice, will give rise to catastrophic failure if the point of greatest tension is treated with a drop of some suitable liquid. It was concluded that the cohesive forces in the plane of greatest tensile strain collapse via the action of wetting and adsorption processes.

Similar behaviour occurs with amorphous polyethylene terephthalate sheet; but here a somewhat different mechanism for the cohesive breakdown is suggested.

If a strip of sheet (approximately $0.1 \times 1 \times 5 \mathrm{~cm}$.) is given a bending stress by wrapping round a steel rod $(1.5 \mathrm{~cm}$. diam.) and then held firmly in a vice, it will initially become opaque in the area of treatment with a spot of acetone, and ultimately fracture.

It has been shown ${ }^{2,3}$ that a series of organic liquids will induce crystallization in amorphous polyethylene terephthalate, particularly if the solubility parameters of the liquids lie within a certain critical range. This process of crystallization is accompanied by an increase in opacity. It is therefore suggested that in the case of the stress-cracking described above, the acetone, or indeed presumably any liquid the solubility parameter of which lies within the permitted 